\section{A Terra e seus Vários Sentidos: por uma Sociologia e Etnologia dos moradores de fazenda na África do Sul contemporânea}

Recebido:

20.07.12

Aprovado:

02.08 .12
Marcelo C. Rosa ${ }^{1}$

Resumo: Este texto é resultado de pesquisas realizadas com o Landless People's Movement, na África do Sul, e tem como tema a relação histórica estabelecida entre os trabalhadores rurais moradores de fazendas de brancos (denominados farm dwellers, em inglês, ou abahlali basimapulazini, em Zulu) e as terras em que vivem. A partir de dados bibliográficos, fontes documentais e pesquisa de campo, defendemos a hipótese de que essas pessoas compõem uma categoria fluida, do ponto de vista das políticas de restituição, de reforma e de direito à terra. Tratar-se-ia de uma categoria em que estariam entremeadas as consequências do apartheid, as transformações na agricultura, as religiões e as leis costumeiras. Trama e fluidez que constituem um problema para antropólogos e sociólogos que se aventuram a lidar com a questão, assim como para os próprios movimentos e ONGs que a representam. Tanto do ângulo das políticas, como dos textos de ciências sociais, esses trabalhadores encarnariam os dilemas de não serem vistos nem como suficientemente modernos, tampouco como tradicionais a ponto de garantirem status teórico no escaninho dos estudos sobre o campesinato e trabalhadores rurais ou no da Etnologia africana clássica

Palavras-chave: Trabalhadores Rurais, África do Sul, Lutas por Terra, Sem Terras, Apartheid.

Introdução ${ }^{2}$

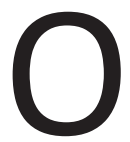

programa de "reforma da terra" foi um elemento central na transição do apartheid para o regime democrático na África do Sul e visava reparar o processo que concentrou cerca de $87 \%$ das terras rurais do país na mão da população branca (correspondente a menos de $10 \%$ da população total), ao longo do século XX (HALL \& NTEBEZA, 2007).
1. Professor do Departamento de Sociologia/UnB Bolsista de Produtividade em Pesquisa do CNPq e Coordenador do Laboratório de Sociologia Não-Exemplar. E-mail: marcelocr@ uol.com.br

2. A pesquisa que dá origem aos debates presentes neste texto tem sido realizada em conjunto com Antonádia Borges e grupos de alunos da Universidade de Brasília e da Universidade Federal Fluminense, a quem agradeço e com os quais compartilho muitas informações. Agradeço também a Emilia Pietrafesa de Godoi e Maria do Rosário Carvalho, por terem me despertado para este problema ao sugerirem a organização de um grupo de trabalho sobre Etnologia e Estudos Rurais, reunido durante o XXXIV Encontro da ANPOCS. 
3. Os farm dwellers podem também ser beneficiários dos programas de redistribuição e restituição, quando legalmente habilitados. O prazo para requerer direitos à terra previsto nos programa de restituição e land tenure para farm dwellers se esgotou em 2001. Segundo o relatório da ONG Nkuzi (2005), cerca de 20.700 pedidos de restituição foram abertos por farm dwellers até aquela data.
Nas áreas urbanas, o principal reflexo dessas medidas foi a segregação espacial entre as cidades (brancas) e as townships (cidades construídas para abrigar a população apartada por ser classificada como não branca), localizadas distantes dos centros comerciais e próximas das áreas industriais.

Nas áreas rurais, o impacto mais visível dessas legislações foi a criação, ao longo do período segregacionista, das chamadas reservas ou bantustões que confinaram a população negra (em si fragmentada conforme critérios supostamente étnicos e linguísticos, estabelecidos pelo regime autoritário, o qual, por sua vez, concedia, ainda, poderes políticos aos chamados chefes tradicionais) (SCHAPERA, 1967; NTSEBEZA, 2005).

Para além do seu confinamento às reservas, a proibição da propriedade da terra por africanos negros, contribui para o incremento de outro tipo específico de relação de trabalho e moradia rural: a residência de famílias negras em fazendas de brancos, em troca da provisão de trabalho ou de pagamento por produção da terra. Esse modo de uso da terra, conhecido em inglês pelo termo labour tenancy, orientou-se por várias formas que misturaram pagamentos em trabaIho, dinheiro ou produtos agrícolas. É também importante notar que, em certos casos, os antigos moradores negros das áreas concedidas para os colonizadores brancos, acabaram por se tornar trabalhadores nas novas fazendas estabelecidas na mesma área em que já habitavam.

Esse breve sumário sobre os efeitos do apartheid, que será retomado a seguir, é importante porque esclarece quais seriam, hoje, os públicos beneficiados pelo programa de reforma da terra em suas três vertentes: restituição, redistribuição e reforma da posse. $O$ alvo nas políticas de restituição são as populações rurais e urbanas removidas para as townships e para as áreas de reserva ou bantustões. A política de redistribuição, por sua vez, busca minimizar o monopólio da agricultura de larga escala na mão de fazendeiros brancos, incentivando a aquisição de terras para população negra. Já a reforma da posse visa garantir o direito à terra para as famílias de trabalhadores negros moradores de fazendas comerciais que, com a legislação pós-apartheid, passaram a ser abrigados sob a categoria paralegal de farm $d$ wellers ${ }^{3}$ (que designa, em inglês, todos aqueles que residem em uma fazenda que não lhes pertence).

Nesse texto, não trataremos do caso da populações urbanas, dos residentes nas antigas reservas - atualmente, áreas sob o governo de autoridades tradicionais - ou dos novos empresários rurais negros. Seu foco principal são as populações rurais residentes em fazendas de brancos chamados na África do Sul, a depender da circunstância, de farm dwellers, labour tenants, squatters ou occupiers (em inglês) e de abahlali basemapulazini (em Zulu). 
Esse grupo específico se torna interessante, entre outras coisas, porque é ele que forma a base do principal movimento pela reivindicação de reforma da ter$\mathrm{ra}^{4}$ do país nesse início do século XXI - o Landless People's Movement (LPM). Apesar disso, pesquisas anteriores sobre tal movimento, realizadas por esse e outros pesquisadores, raramente tematizam as múltiplas e, por vezes, divergentes experiências históricas de pessoas hoje classificadas com o amplo termo farm dweller. Do mesmo modo, tais trabalhos tampouco buscaram relacionar as possíveis peculiaridades de suas trajetórias a suas ações coletivas, demandas e à própria noção de sem terra defendida em suas lutas (ROSA, 2012; GREENBERG, 2005; JAMES, 2007).

Nossa hipótese principal, parafraseando as conclusões críticas de Archie Mafeje (1975, p. 184) para o contexto dos estudos de religião na África do Sul, e também de outros autores como Du Toit (1994), é de que essas pessoas compõem uma categoria fluida, do ponto de vista das políticas de restituição, de reforma e de direito à terra. Farm dweller trataria de uma categoria em que estariam entremeadas as consequências do apartheid, as transformações na agricultura, as religiões e as leis costumeiras. Tal trama e fluidez constituem um problema para antropólogos e sociólogos que se aventuram a lidar com a questão, assim como para os próprios movimentos e ONGs que a representam. Tanto do ângulo das políticas, como dos textos de ciências sociais, esses trabalhadores encarnam os dilemas de não serem vistos nem como suficientemente modernos, tampouco como tradicionais a ponto de garantirem status teórico respectivamente nos escaninhos dos estudos sobre o campesinato e trabalhadores rurais, ou no da Etnologia africana clássica.

Para evitar essas dilemas, proponho, metodologicamente, fazer neste texto um apanhado de bibliografias e alguns dados de pesquisa secundários e próprios que tematizaram casos de residentes em fazendas em diversos contextos. Esse conjunto de textos e dados, que não costumam tratar dos mesmo temas, permitirá que sigamos a ideia de Latour (2005) de recompor o social. Ou seja, ao invés de aceitar os escaninhos clássicos das ciências sociais para o tema (relações de trabalho ou cultura) e deles partir para a pesquisa (como faz a escassa bibliografia disponível), vamos, aqui, compor um farm dweller pelas suas relações com pessoas e objetos que deixam marcas em suas ações cotidianas e que se tornaram visíveis para vários pesquisadores. Essas composições serão simétricas, do ponto de vista de que tentam considerar que todas as relações são importantes, e assimétricas, do ponto de vista de que nem todas elas podem ser exploradas e descritas da mesma forma.

Nesse sentido, ao longo das páginas que se seguem, procurarei analisar e descrever a categoria de possíveis beneficiários da reforma da terra, a partir de uma relação triangular entre a legislação que regulamentou essa forma de
4. No caso da África do Sul e do LPM, todos os documentos oficiais utilizam a expressão land reform para caracterizar as políticas de redistribuição de terras. Para uma análise das diferenças entre as ideias de reforma agrária e reforma da terra, ver Rosa (2012), que compara os usos desses termos no Brasil e na África do Sul. 
5. Essas pesquisas envolveram a realização de entrevistas individuais e coletivas, etnografia de eventos e da vida cotidiana de militantes do Landless People's Movement e pesquisa de arquivo. As referências, no plural, se referem a pesquisas realizadas coletivamente com Antonádia Borges e grupos de alunos da UnB e da UFF. trabalho século XX, as formas de organização da vida nas terras de fazendeiros e informações secundárias sobre a situação atual daqueles vivem dentro de fazendas. Além de dados bibliográficos, utilizarei, como fonte, pesquisas feitas por ONGs e breves relatos etnográficos de nossas próprias pesquisas de campo realizadas entre 2005 e $2012^{5}$.

Acredito que, ao reunir em um mesmo texto algumas destas dimensões analíticas, abrirei as portas para, não apenas, conectar diferentes estudos, mas, principalmente, para demonstrar as dificuldades de enquadrar em um tipo específico e único de demanda por terra ou, em um unívoco movimento social, as inúmeras formas que tal estilo de vida pode assumir. Nesse sentido, o texto cumpre o papel de apresentar os farm dwellers àqueles que tenham interesse em compreender as políticas de restituição e as demandas por terra contemporâneas na África do Sul. Ao final do trabalho, pretendo, portanto, que os leitores possam compor suas imagens desses processos e próprios dos moradores de fazenda também a partir dessas dificuldades classificatórias.

\section{Transformações Históricas da Labour Tenancy}

A maior parte dos estudos sobre os residentes negros em fazendas de branco, realizados antes do final do apartheid, tratou de discutir as formas de extração de mais-valia e composição da renda rural no país. Nessa perspectiva, trabalhos como os de Marcus (1989), Wilson, Kooy e Hendrie (1977) e Roberts (1959) analisam as relações sociais desses trabalhadores a partir de seu enquadramento na história da agricultura comercial do país, do papel do Estado e dos efeitos do apartheid.

Em todos os estudos acima, constata-se a sobreposição das medidas segregacionistas do apartheid e da criação de formas de superexploração do trabalho nas fazendas. As formas mais evidentes da associação entre racismo e exploração econômica podem ser encontradas no conjunto de leis e decretos publicados entre o final do século XIX e o final da década de 1940 e que formam a base do que veio a ser o regime de apartheid (iniciado formalmente em 1948).

Como aponta Ntsebeza (2007), o Glen Gray Act, de 1894, já previa taxação do trabalho negro e sua forçosa submissão ao labor nas fazendas como única forma de evitar tal pagamento. Com medidas legais dessa ordem, a condição de Labour Tenant começa a ser tornar compulsória, tal qual uma versão mais sofisticada da relação entre senhores e servos (termo usado na mesma lei).

Apesar da importância da lei de 1894, o Natives Land Act, de 1913, se convencionou como o marco do início do apartheid, pois nele foram previstas as 
reservas de território para a população negra. Além das criação das reservas que previam o confinamento da maioria da população a somente $10 \%$ da área do país, a lei de 1913 também regulamentou a prestação de trabalho nas fazendas.

Naquele momento, a associação entre trabalhador rural e labour tenant era tão óbvia, que, na lei de 1913, a categoria trabalhador rural foi definida da seguinte forma:

Trabalhador rural deve significar o nativo que reside de boa fé em uma fazenda, mas não necessariamente empregado de forma contínua pelo dono ou arrendatário no serviço doméstico ou em tarefas agrícolas (grifo do autor) ${ }^{6}$.

A mesma lei previa, ainda, que somente poderiam ser considerados trabalhadores rurais aqueles que provessem ao proprietário das terras pelo menos noventa dias de trabalho por ano.

É importante notar que, ao longo do século $X X$, tanto a legislação, quanto as formas de trabalho na fazenda variavam de região para região. Entre os autores consultados, é unânime a ideia de que o uso de labour tentants fora predominante em certas áreas, como o atual norte de Kwazulu-Natal, parte dos antigos Transvaal, Free Orange State e na região de Grahamstown, atual Eastern Cape. Segundo Marcus (1989), essa situação teria predominado até o início institucional do apartheid, em $1948^{7}$.
6. http://www.polity.org.za/polity/govdocs/legislation/ misc/nla1913.html

7. Em outras regiões, teriam predominado o trabalho assalariado ou o trabalho de homens que moravam em alojamentos, sem direito a trazer suas famílias para as fazendas.

\section{Mapa 1 - Divisão politica da África do Sul durante o apartheid}

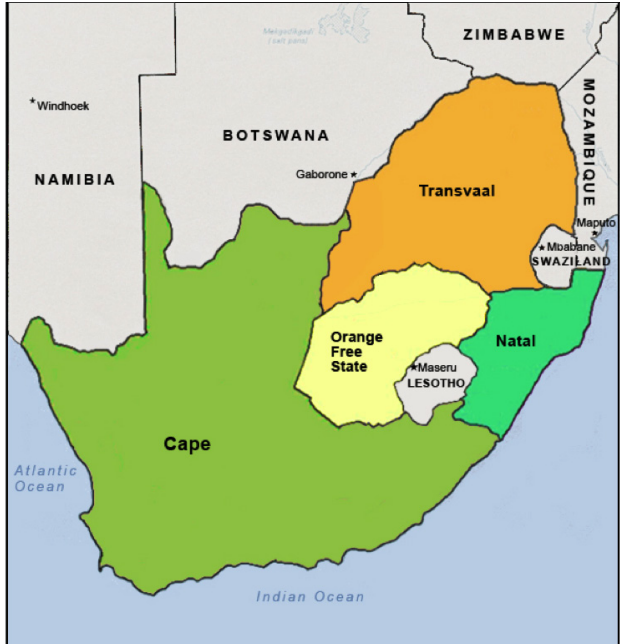

Fonte: Matrix, Michigan State University 
8. É importante notar que o "sistema de seis meses" era vantajoso para o fazendeiro porque o eximia de pagar salários para seus trabalhadores fora época das safras.
Em 1926, a lei Master and Servants se estendeu apenas para Natal e Transvaal, aumentando o período de prestação compulsória de serviço nas fazendas para seis meses. Além disso, a definição de labour tenant passou a incluir a esposa e os demais dependentes do trabalhador, e introduziu também a expulsão sumária da fazenda se algum desses membros não prestasse suas obrigações de trabalho para com o fazendeiro (MARCUS, 1989, p. 47).

Em 1936, o Native Trust and Land Act teria representado uma nova tentativa de controlar a prática de labour tenancy e também de regular a ocupação de área rurais por famílias negras. Nessa lei, que ampliou a área das reservas para cerca de $13 \%$ do território do país, ficou estabelecido que famílias negras somente poderiam morar fora desses territórios na seguintes condições: se eles fossem proprietários registrados, ou servos dos proprietários, tenants ou ocupantes registrados, mulheres ou filhos de "nativos" que obedecessem às condições anteriores, ou clérigos ou professores, além de idosos e pessoas doentes com autorização (ibidem, p. 59). Reafirmando as intenções da lei de 1926, ficou também proibida, em certas áreas do país, a livre migração de trabalhadores rurais para ocupações urbanas ou industriais.

Para essa autora, as medidas de controle do fluxo de mão de obra contribuíram, paradoxalmente, para uma diminuição significativa da força de trabalho disponível nas fazendas, ao longo do ano. Com 180 dias livres de obrigações legais para com os fazendeiros, muitos dos tenants podiam migrar temporariamente (mediante autorização dos donos de terras) para as zonas industriais, especialmente as de mineração, para complementar sua renda monetária, como veremos adiante ${ }^{8}$. Essa migração temporária permitia aos fazendeiros pagarem salários irrisórios e também desobrigava de remunerar seus trabalhadores na entressafra.

Em 1952, foram estabelecidos Labour Bureaux, que passaram a controlar o fluxo de mão de obra entre fazendas e das fazendas para as zonas urbanas. Para conseguir um novo emprego, todo trabalhador rural precisava certificar que havia sido dispensado da fazenda anterior e ter autorização para se apresentar na próxima fazenda. A intenção de tais escritórios teria sido de controlar o volume de mão de obra em cada uma das fazendas, de modo que houvesse tanto um equilíbrio na força de trabalho disponível para cada fazendeiro, como também a garantia de migração de uma parte da população negra para as cidades. A partir de 1956, foram criados ainda os Labour Tenants Control Boards, compostos por três fazendeiros e um membro do Native Affairs Department. Por meio desse conjunto de medidas de cerceamento, a outrora relativa conveniência do sistema para labour tenants e seus familiares, apontada por Sato (2006) e Atkinson (2007), tornou-se cada vez mais irrisória. Ao cabo, como afirmam Marcus (1989) e Roberts (1959), tanto o governo, quanto uma parcela dos fazendeiros 
passaram a apoiar medidas para abolir a labour tenancy e criar uma classe exclusiva de trabalhadores rurais que não tivessem direito à terra.

Medidas tomadas ao longo da década de 1950 estabeleciam taxas específicas que deveriam ser pagas pelo fazendeiro para cada labour tenant registrado, e aumentavam o valor das taxas pagas pelas cabeças de gado que os trabalhadores mantinham nas fazendas (foram taxados, ainda, porcos e cabras, anteriormente excluídos de qualquer cobrança). De acordo com essas leis, a partir de fevereiro de 1956, nenhum novo trabalhador poderia mais ser registrado como labour tenant.

Em 1969, uma nova emenda à lei de 1936 aboliu a prática da labour tenancy em Orange Free State, Transvaal e em quatro distritos de Natal. Segundo Marcus (1989), a relutância em extinguir o sistema nessa última área (atualmente Kwazulu-Natal) devia-se à grande dependência que os fazendeiros da região tinham em relação à mão de obra desse tipo de trabalhador. Segundo os números apresentados pela autora, oriundos de diferente fontes, no início da década de 1960, havia 200 mil labour tenants registrados na região norte e central daquela província (de um total estimado entre 750 mil e 1 milhão), esse número foi reduzido para apenas 24 mil, em 1970, e para, ao menos em termos formais, zero em 1980. Ou seja, em 20 anos, se extinguiu quase por completo os registros de uso da terra por parte de trabalhadores rurais.

Essa versão linear do processo tem sido usada para demonstrar as formas de modernização da exploração do trabalho na região em um contexto de igual modernização da agricultura. No entanto, ela não espelha as condições pelas quais, mesmo que informalmente, a labour tenancy continuou a ser praticada nessas mesmas áreas.

\section{Legislações e Remoções}

O destino e as resistências dos trabalhadores ao processo de "modernização" e segregação é o tema da tese de Sato (2006), que analisa o caso da cidade de Weenen, atual Kwazulu-Natal e do relatório do Surplus Peoples Projetc (SPP, 1983). Baseada em dados censitários e nos levantamentos sobre as remoções de famílias negras para as townships (cidades segregadas criadas pelo apartheid para abrigar a mão de obra urbana negra) ou áreas de reserva, a pesquisa de Sato estima que, em Weenen, a população das fazendas teria sido reduzida de 16 mil para 9 mil pessoas, entre 1964 e 1970. 
Mapa 2 - Divisão política da África do Sul após 1994

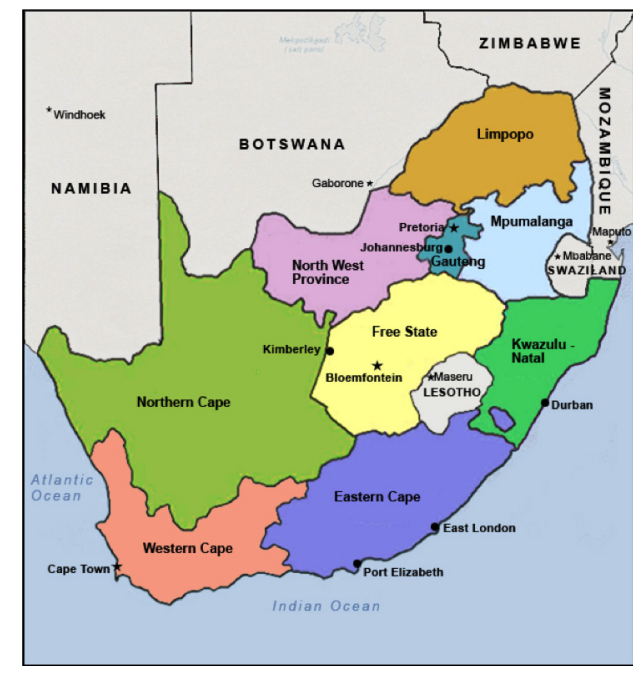

Fonte: Matrix, Michigan State University

Segundo Sato (2006, p. 239), na região do estudo, o prazo final para registro de todos os labour tenants venceu em 1968. Quando um grupo de fazendeiros da área não cumpriu a determinação e perdeu o direitos de usar esse tipo de mão de obra, legalmente, houve um acordo geral entre eles para que ninguém mantivesse trabalhadores em suas fazendas de forma a não prejudicar os demais. Segundo esse trabalho, quando os seis meses regulamentares de trabalho do ano de 1968 terminaram, todos os fazendeiros propuseram um novo e único contrato de trabalho assalariado (com valores irrisórios) para seus trabalhadores. Aqueles que não aceitaram, logo a seguir receberam ordem despejo e foram classificados como invasores de suas próprias casas, tendo apenas apenas duas semanas para deixar as áreas. Para que novos trabalhadores não ocupassem as antigas moradias, as casas foram queimadas e o gado apreendido - afinal, se tratavam de pessoas que passaram a ser legalmente invasores - ou comprado pelos fazendeiro a preços módicos. Somente nessa área, 233 kraals (unidades de moradia familiares que serão trabalhadas a seguir) foram removidos para assentamentos emergenciais em outras áreas com o aval e ajuda do governo central.

Essas medidas, somadas à reação dos trabalhadores à oferta de salários irrisórios, afetaram drasticamente a oferta de mão de obra nas fazendas da região. Em 1970, foi proposta uma moratória na remoção de trabalhadores rurais e todos aqueles fazendeiros que tinham labour tenants registrados antes daquele ano puderam manter seus trabalhadores. $O$ relaxamento das medidas contribuiu, também, para que algumas famílias expulsas pudessem voltar para suas 
fazendas de origem mediante novos contratos, que ofereciam em geral o dobro do salário proposto no ano das remoções. Para Sato (2006, p. 241), os eventos de Weenen foram fundamentais para a sobrevivência da labour tenancy em toda aquela região e para a existência das histórias atuais de conflito. Desde então, as expulsões de trabalhadores resultaram de ações privadas de fazendeiros e não de grandes projetos estabelecidos pelo apartheid e sua legislação ${ }^{9}$.

A cronologia de legislações e definições legais aqui apresentada ajuda a compreender as formas pelas quais o Estado procurou regular tais práticas, mas ainda não representa um reflexo preciso do que aconteceu nas fazendas, longe dos olhos do governo. Mesmo nos períodos de maior controle, havia migrações entre fazendas e áreas industriais. Da mesma forma, após a extinção da labour tenancy, milhares de família ainda continuaram a viver em fazendas e a trocar uma fazenda por outra em busca de moradia.

\section{As Várias Formas da Labour Tenancy}

Apesar das definições formais que previam o número de trabalhadores e os limites da relação entre fazendeiros e tenants, as formas concretas de vida nas fazendas variavam caso a caso e, principalmente, de região para região. A maioria dos trabalhos disponíveis sobre esse tipo de trabalho rural, ao longo século, está concentrada na atual área de Eastern Cape, como pode ser visto em Roberts (1959), Robertson (1967) e em Atkinson (2007). Para a área de Kwazulu-Natal, os trabalhos mais completos são os de McClendon (2002), Sato (2006) e de Loudon (1970). Mais recentemente, o relatório da AFRA (AFRA, 2008) sobre os farm dwellers, no distrito de Amajuda, se constitui numa das poucas fontes atualizadas sobre a situação nas fazenda da região. É a partir dos relatos contidos nesses trabalhos que apresentaremos um breve painel sobre as relações sociais dentro das fazendas e as formas de uso da terra. Aqui, pretendemos cobrir desde os aspectos trabalhistas até o que poderíamos chamar, na falta de expressão melhor, de etnologia dessas relações (incluindo temas como religião, gênero, parentesco, dentre outros).

Nas histórias de residência e de relação de trabalho levantadas por Robertson (1959), a moda estatística do tempo de residência nas fazendas de Grahamstown foi de mais de seis anos, com vários casos de residentes no mesmo local entre 20 e 40 anos. Em tempos tão longos de residência, não seriam somente as relações de trabalho que ligariam os trabalhadores às suas terras, pois alguns trabalhadores estavam há mais tempo na fazenda que o próprio dono.

É visão corrente, em todos os estudos sobre essa categoria, que se tratava de uma relação que apesar de desigual, beneficiava relativamente tanto
9. Esse tipo de expulsão foi tema de um importante survey nacional realizado pela ONG Nkuzi, na primeira metade da década de 2000. Naquela pesquisa, são apresentados dados que indicam que o número de pessoas expulsas, de forma legal e ilegal, de fazendas, entre 1984 e 2004 , seria da ordem 1,7 milhão em todo o país (NKUZI, 2005). Um achado importante desse estudo é a correlação positiva entre a provação de novas legislações para proteger os direitos dos farm dweller e o aumento das expulsões. Essa mesma tendência foi encontrada por Sigaud (1979), em seu estudo sobre os direitos de trabaIhadores rurais no Brasil. 
10. Além de regular as quantidades de bebida a ser fermentada, também era a proibida a adição de ingredientes que aumentam seu teor alcoólico como mel e açúcar. o fazendeiro como os moradores. Aos fazendeiros, obviamente por permitir a exploração contínua do trabalho familiar com custos reduzidos de salário ou sem custo algum. Já para os trabalhadores (apesar de pouco eficaz do ponto de vista econômico), a moradia nas fazendas representava uma das raras alternativas para continuar a viver em terras já ocupadas por eles, antes da sua transformação em propriedade privada de brancos, ou para evitar sua remoção para reservas estabelecidas em 1913.

Esse tipo de conclusão contribuiu para que autores como Atkinson (2007) e Robertson (1959) encontrassem, no termo paternalismo, a melhor forma descrever as relação entre fazendeiros brancos e seus trabalhadores negros. Essa relação se estabelecia a partir da premissa de que não havia um aparato legal que regulasse as condições de trabalho (apenas estavam estabelecidas a quantidade de dias a serem trabalhados). Também não haviam organizações coletivas que representassem diretamente os interesses dos trabalhadores. Para Robertson (1959, p. 63), essa condição permitia que os fazendeiros determinassem os termos da relação muito mais como privilégios por eles concedidos, do que como direitos. Nas descrições das entrevistas feitas por essa autora com donos de fazendas, são enfatizadas, por exemplo, passagens nas quais o fazendeiro demonstra preocupação com o fato de os trabalhadores serem inábeis para lidar com seus recursos monetários ou com a comida recebida.

Um dos aspectos mais relevantes dessa relação pode, segundo Robertson (1959), ser justamente observado na alimentação dos trabalhadores. Para ela, a dieta alimentar estava diretamente vinculada à forma de remuneração do trabalho que era composta, em sua maior parte, por pagamentos em espécie, incluindo comida, e não em dinheiro. Esses alimentos seriam aqueles que os patrões acreditavam os mais apropriados e não necessariamente aqueles desejados pelos próprios trabalhadores.

Além da alimentação, em uma seção chamada de condições não materiais de trabalho, o livro de Robertson aponta para questões que são cruciais até os dias de hoje, como as permissões para consumir bebidas alcoólicas e receber visitas. Apesar de ela mesma afirmar que não haviam leis que regulassem o trabalho, haviam leis que limitavam, por exemplo, a quantidade de cerveja tradicional feita a partir de milho e sorgo que poderia ser fermentada por cada família (na região do estudo, o máximo era de quatro galões $)^{10}$. Como o consumo de cerveja está ligado à rituais como os de iniciação masculinos, casamentos e velórios, sua limitação interfere também na regulação das vistas que cada família poderia receber em seu kraal para consumi-la.

Esse tipo de controle denota uma das características fundamentais das famílias que vivem dentro de fazendas, atualmente: elas não são e quase nunca foram 
livres para celebrar seus rituais e nem mesmo para receber visitas.

Apesar disso, Atkinson (2007) afirma que as fazendas não poderiam ser consideradas como instituições totais, onde o fazendeiro controlava a tudo e a todos. Para essa autora, o fato de uma fazenda ter, em média 4 a 6 kraals, contribuía para a criação de laços sociais fortes entre os moradores que envolviam, obviamente, o compartilhamento da mesma língua e do mesmo chefe tradicional (que, em geral, está associado a um clã). As festas, casamentos, funerais e a afiliação de muitas dessas famílias às igrejas chamadas, por ela, de african nationalists, constituíam um âmbito da vida social de seus trabalhadores no qual a autoridade do senhor de terras não se impunha totalmente. Segundo ela, quando algumas famílias já tinham vivido por gerações em uma mesma terra, elas sentiam que tinham o mesmo direito a viver naquela terra que o próprio fazendeiro (que, em geral, havia comprado a fazenda já com os trabalhadores vivendo nela) (ATKINSON, 2007, p. 43) ${ }^{11}$.

\section{Da Implicação Etnológica da Labour Tenancy}

A forma de moradia básica desse tipo de trabalhadores nas fazendas é o kraal ou homestead (cuja forma espacial pode ser observada nas fotos abaixo), que foi alvo de extensos estudos como os de Kuper (1980).

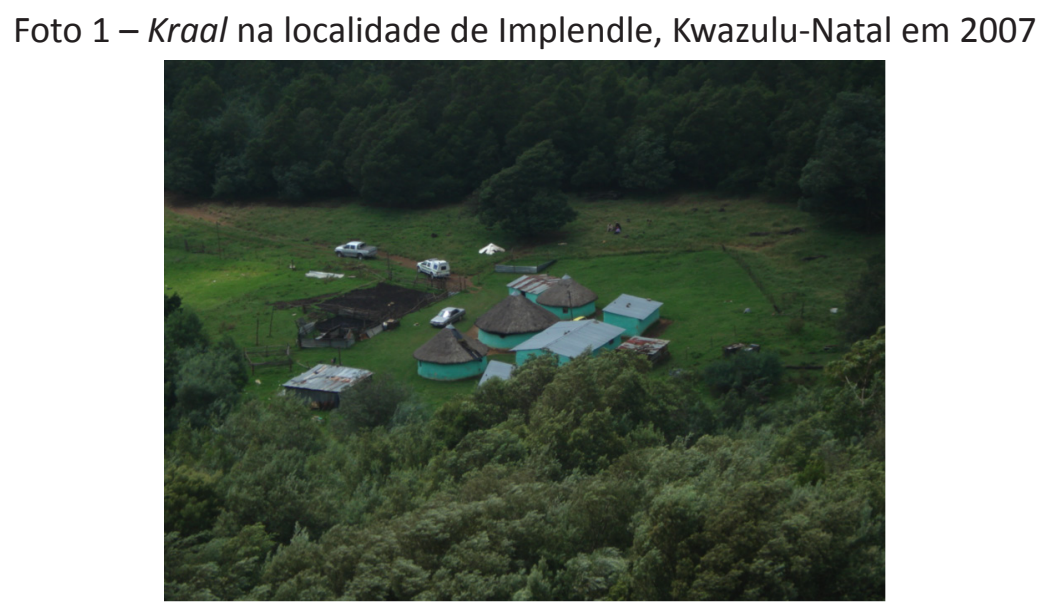

11. Um bom exemplo pode se encontrado no trabalho de Sundekler sobre as religiões cristãs na região de Kwazulu-Natal: "O líder de igreja de tipo chefe não é incomum nas fazendas. Ele pode ser empregado durante os dias da semana como um chefe tradicional e o fazendeiro pode confiar na sua influência sobre outros africanos negros na fazenda como um todo" (SANDEKLER, 1948 , p. 88).

Autores: Antonádia Borges e Marcelo Rosa

A principal diferença, do estudo de Kuper para a situação que descrevemos é que esse autor analisa o kraal em sua forma estrutural na cosmologia Nguni (tronco linguístico predominante no sul da África) sem se referir ao tipo de terra no qual ele se inscreve, se está em território classificado como tradicional ou em uma fazenda privada, como é o caso aqui. 
12. O fato de a filha casada residir com seu pai representa uma exceção ao modelo de virilocalidade predominante na literatura sobre o kraal.

13. McClendon (1997, p. 48), em seu estudo sobre a posse de gado por labour tenants na então província de Natal, afirma: "Africanos (negros) acumulam gado por muitas razões: para prover leite, para servir aos ancestrais por meio do sacrifício e distribuição de carne e para terem bois que sirvam animais de tração. A razão mais importante, todavia, continua a ser o estabelecimento e continuidade de relações de casamento entre as famílias. Assim como em muitas partes do sul da África, o dote era uma característica essencial do casamento entre os africanos falantes de zulu em Natal, onde a transferência do dote é conhecida como ukulobola". Esse mesmo autor também se vale do argumento de Kuper (1982): "doações de gado eram meio típicos de se estabelecer relações políticas" (McCLENDON, 1997, p. 49).

14. Robertson (1959, p. 41), citando um fazendeiro: Nós temos que ser muito cuidadosos ao pedir que eles reduzam o número de suas
Em cada kraal (ou homestead) estudado por Loudon (1970, p. 79) na região de Natal, viviam "tipicamente" um homem com uma ou duas esposas, com seus filhos homens casados, suas esposas e netos, além dos filhos e filhas que ainda não casaram. Nessa pesquisa sobre nove fazendas na região de Drakensberg, havia 51 kraals, cujos membros pertenciam a mais de 16 clãs diferentes. Esses dados são importantes, como ressalta o autor, porque é por meio dos clãs que se organizam os casamentos (exogâmicos) e é no kraal de cada família que se cria o gado para pagamento do lobola (o dote ou preço da noiva como se convencionou chamar na antropologia). Outro aspecto importante, também ressaltando por Robertson (1967), é o fato de que as relações clãnicas mantinham as famílias que viviam em fazendas de brancos subordinadas tanto ao próprio fazendeiro dono da terra quanto à autoridade de chefes tradicionais ou tribais.

Este tipo de descrição raramente aparece nos estudos sobre labour tenants que optam por traçar apenas a vida laboral dos envolvidos. No estudo de Robertson (1959), por exemplo, há um apêndice sobre a história de um dos trabalhadores rurais entrevistados; nele não encontramos descrições sobre outras atividades realizadas pela família do Senhor Smile que não fossem o trabalho. Entrevistado em 1957, quando tinha 106 anos de idade, de sua vida apenas apreendemos que fora sempre um morador de fazendas de brancos na região de Grahamstown. Na época da pesquisa, ele vivia em um kraal com dois filhos e suas esposas, uma filha e seu marido e vinte quatro netos em duas casas ${ }^{12}$. No kraal, haviam 15 vacas e seis cabras. Ao longo das páginas daquele estudo, porém, não temos qualquer pista sobre as implicações sociais de famílias extensas viverem dentro de fazendas. Como na maioria dos outros estudos, tudo que não seja relativo ao trabalho tende a ser resumido aos termos "cultura" e "tradição" (em geral nunca devidamente explicados).

\section{Gado}

A mesma literatura é quase unânime quanto à necessidade de posse de gado pelos labour tenants. Além de ser fundamental para o pagamento e recebimento do lobola, o gado como ressalta Robertson (1959), não pode ser considerado somente uma fonte de renda, pois ele é uma fonte de prestígio e riqueza não econômica ${ }^{13}$. Em todas as casas que visitamos, ao longo da pesquisa e em todos os trabalhos até agora citados, os labour tenants possuíam algumas cabeças gado. Quanto mais gado se possui, mais prestigiado é o dono do kraal. Nessa pesquisa, a autora e os próprios fazendeiros identificam no cerceamento da manutenção de gado uma das principais causas de abandono do emprego nas fazendas ${ }^{14}$.

A manutenção do gado dentro das fazendas varia de acordo com a propriedade, 
o tenant e o fazendeiro. Em certos casos, como os apontados por Sato (2006) e Robertson (1959), o gado dos trabalhadores se misturava com o dos patrões. Em casos como os que vi em Kwazulu-Natal, nos últimos anos, o gado dos trabalhadores tinham espaços restritos para circular e qualquer mistura com os animais do fazendeiro poderia ser considerada uma ofensa grave. Isso também tem implicações diferentes para uma fazenda de produção de grãos ou uma fazenda de criação de gado. Nas primeiras, o gado é sempre uma ameaça, porque pode destruir as lavouras, nas segundas porque pode contaminar o gado do fazendeiro (pois se supõe que os animais dos trabalhadores não recebem a mesma atenção veterinária que os do proprietário).

Existiam e continuam a existir, também, variações quanto ao pagamento ou não de uma taxa pelos trabalhadores por cada cabeça de gado mantida nas fazendas. Além da taxa por cabeça de gado, houve sempre um número limite de cabeças em cada fazenda.

Um labour tenant nunca pode descuidar de seu gado sob pena de ele ser confiscado pelo fazendeiro ou pela prefeitura, quando alguma regra é desobedecida. Nos casos de confisco, o dono do gado precisa pagar pelo transporte dos animais, pelo aluguel da área onde ficam retidos e arrumar uma forma de transportar o animais de volta para sua terra. $\mathrm{O}$ gado também pode ser abatido para rituais como enterros e casamentos e, em famílias nas quais os rendimentos monetários são escassos, possuir gado para abater é tão importante quando ter um lugar para enterrar seus entes.

Em uma análise do papel do gado na vida social de labour tenants, na província de Mpumalanga, James (2007) afirma que, naquela, região o gado também era uma forma de investimento dos recursos obtidos durante as migrações temporárias para trabalho na cidade. Para a autora, naquela região, a vida dos farm dwellers era marcada por um "delicado equilíbrio entre terra, trabalho e gado" (JAMES, 2007, p. 144). Citando Steinberg (2002), James também afirma que, para os homens jovens, a impossibilidade de criar gado afeta, além do pagamento do lobola, a possibilidade de que os filhos tenham a paternidade reconhecida e, por conseguinte, que venham a ser parte da linhagem de seu pai (que deve oferecer gado à família de sua esposa para cada criança que nasce $)^{15}$.

\section{Túmulos}

Citando um survey realizado em 2003, Artkinson (2007, p. 100) afirma que, dos 57 fazendeiros entrevistados, 36 ainda permitiam a realização de funerais e enterros em suas fazendas, enquanto os demais 21 haviam abolido tais práticas. Sem tratar de qualquer dimensão etnológica da questão, a autora aponta para

cabeças de gado em nossas fazendas: são geralmente os melhores trabalhadores que possuem mais gado e nós corremos rico de perdê-los ao insistir que vendam seus rebanhos".

15. Nesses casos, enquanto o pai não pagar o gado necessário pela criança, ela permanece sob os cuidados da linhagem da família da mãe vivendo em seu kraal. 
uma série de conflitos sobre os funerais que haviam eclodido e causavam apreensão nos fazendeiros. Esses conflitos certamente tinham relação com o fato de que ter ancestrais enterrados (graveyards) em uma fazenda pode, sob certas circunstâncias legais, levar o trabalhadores a apresentar um pedido legal de direito sobre aquele pedaço de terra (previsto no Extension of Tenure Security Act de 1997) (JAMES, 2007).

Além de poderem, eventualmente, usar as covas como provas de um direito à terra, muitas famílias afirmam que os graveyards são lugares que precisam ser visitados para a realização de rituais, especialmente de consulta aos ancestrais (AFRA, 2005). Borges (2011), analisando o caso de uma família de labour tenants, em Kwazulu-Natal, narra a tortuosa batalha de um dos membros do LPM para trazer não apenas o corpo, mas o espírito de sua esposa para o kraal onde estavam enterrados seus parentes (ela havia falecido em um acidente automobilístico longe de sua casa). Ambas as atividades requeriam a permissão do fazendeiro, pois, além do espaço para a cova, haviam também que comparecer os parentes vindos das cidades e de outras fazendas. No mesmo artigo, vemos a descrição de uma série de eventos presenciados em Kwazulu-Natal, entre 2006 e 2010, nos quais moradores de fazendas buscavam enterrar dentro de seu kraal parentes que haviam deixado a fazenda para trabalhar nas cidades.

Para James (2007, p. 18), a importância atual das graves teria mais relação com o desejo de grupos, cuja vida social foi severamente atacada pelo apartheid, assegurarem seu lugar em suas antigas linhagens do que em alguma necessidade tradicional. Para ela, em sua pesquisas anteriores, não haviam indicações de que práticas religiosas "costumeiras" de relação com os ancestrais tivessem que ser realizadas no exato local no qual foram enterrados. Ainda segundo essa autora, nos locais por ela pesquisados não havia qualquer atenção especial aos graveyards, que, na maioria dos casos, estavam "simplesmente" dentro dos currais.

A visão de James, no entanto, pode ser contestada pelo trabalho de Bunn (2002) sobre os grave sites dos grupos Nguni, na era colonial. Para esse autor, os colonizadores brancos e seus soldados e a maioria dos etnógrafos dos rituais mortuários do século XX, também tinham dificuldade de reconhecer a dimensão simbólica dos graveyards Xhosas e, por isso, davam pouca importância ao que Ihes parecia um lugar abandonado. Segundo Bunn (2002, p. 66), as covas dos Xhosa não se constituíam em elementos visíveis, destacados da paisagem (como eram e continuam a ser as covas ocidentais). Seu valor residia no fato de serem tecidas junto ao espaço temporal do kraal. Nesse contexto, os graveyards não estão simplesmente dentro do curral, eles devem estar lá por uma série de razões, principalmente porque é no curral que descansam os ancestrais. $\mathrm{O}$ argumento que se segue é de que os graveyards são importantes, não pelo seu apelo visual como de um túmulo de cemitério - e aqui temos um limite claro do olhar do 
etnógrafo -, mas pelo sua relação simbólica com o espaço de moradia de vivos e de mortos que vivem.

Centrais nos depoimentos colhidos em nossa pesquisa, nos documentos da ONG que contêm narrativas sobre o uso da terra em fazendas (AFRA, 2005), e nas reivindicações descritas por Borges (2011) e Rosa (2012), as covas são um elemento fundamental do kraal e da vida coletiva nas fazendas. Mesmo que, aos olhos de brancos, os graveyards pareçam abandonados ou sem importância, na vida cotidiana das pessoas que visitamos, ao longo dos últimos anos, a tumba tem um papel narrativo importante na decisão de querer continuar vivendo em uma fazenda.

\section{Curandeiros e Medicina Tradicional}

Histórias que envolvem famílias de labour tenants estão presentes também em alguns estudos clássicos e recentes sobre as religiões locais. Bergulund (1975), em seu artigo sobre homens com poder de proteger fazendas, animais e homesteads das tempestades, apresenta-nos o caso do senhor W., morador do norte de Kwazulu-Natal que tinha um kraal nas terras de um fazendeiro branco. Segundo o autor, W. era muito procurado por pessoas de outras localidades para proteger suas terras dos efeitos de tempestades. O senhor W., além de receber pessoas em seu Kraal que desejavam contratar seus serviços, vivia ali com 4 esposas, 19 filhos e pagava renda para o dono da terra que concordava com suas atividades. Além disso, seu filho também trabalhava para o fazendeiro. Para realizar a proteção contra os raios e tempestades, ele precisava de remédios feitos com ervas e partes de animais que, obviamente, devem ser obtidos nas fazendas durante incursões que o levavam para espaços mais amplos que seu kraal.

Caso semelhante encontramos já em 2007, em nossa pesquisa com o Landless People's Movement, em uma região muito próxima e trabalhado por Borges (2010). O caso do Sr. Impendle, um sangoma (curandeiro e diviner), que lutava para manter seu kraal intacto em uma fazenda que havia sido redistribuída pelo programa sul-africano de reforma da terra. Mesmo após todos os demais trabaIhadores da fazenda terem sido expulsos, ao longo das décadas de 1970 e 1980, o Sr. Impendle permaneceu em seu lote, recebendo pessoas que precisavam de aconselhamento ou mesmo de cura para alguma doença. Como resultado disso, ele acumulou algum capital e gado, além de ter alguns membros de sua família extensa morando com ele. Em seu kraal, haviam sete casas (três delas eram casas rituais). No dia de nossa visita, uma das lideranças do LPM estava mediando um conflito entre ele e as famílias que haviam recebido a terra em restituição do governo (antigos moradores da mesma fazenda). A questão em pauta era como demarcar a área de cada um de forma que ninguém fosse prejudicado. Para o senhor Impendle, não era apenas a questão de ter um pedaço de terra do mesmo tamanho ou qualidade dos demais. Ele precisava manter seu kraal próximo 
16. Filial contract nas palavras de McClendon (2002, p. 145). de uma pequena área de floresta e de uma montanha para continuar a receber as visitas dos vivos e dos mortos que precisam de seus serviços. Sem isso, ele não poderia mais executar as curas e interpretações que sempre lhe haviam garantido uma certa renda, e nem mesmo continuar a cumprir com seu próprio destino, já que para se transformar em sangoma é preciso receber um chamado de seus ancestrais.

\section{O Kraal, a Família e as Formas da Labour Tenancy}

O conjunto de leis que passaram a regular essa forma de trabalho teve também impacto na vida social das famílias de labour tenants. Em seu estudo sobre gênero e gerações entre labour tenants, em Kwazulu-Natal, na primeira metade do século XX, McClendon (2002) demonstra como haviam muitas interseções e conflitos entre as novas regulamentações e "leis costumeiras" seguidas por algumas dessas famílias.

Trazendo à tona casos de disputa em cortes tradicionais após a implementação do sistema dos seis meses (mencionado anteriormente), McClendon (2002) afirma que o contrato de labour tenant implicava também contratos intrafamiliares $^{16}$. Como vimos acima, todos os membros da família estavam envolvidos na relação com os fazendeiros. Para esse autor, um dos elementos chave dessa relação era a garantia de que os filhos e as mulheres do chefe do kraal iriam estar sempre disponíveis para prover trabalho como uma extensão de sua própria pessoa.

Em termo dos filhos homens, a contrapartida para o fornecimento de trabalho era de que o pai assumisse o pagamento do lobola (dote na forma de gado), pelo menos, do filho mais velho. Sob tais condições, os filhos homens também eram usados como moeda de troca nesse sistema, pois podiam migrar, durante os seis meses livres, para as cidades ou, ainda, substituir seus pais, fornecendo trabalho nas fazendas quando estes migravam. No caso de migrarem, os filhos ficavam também obrigados a enviar parte de seus ganhos para a manutenção do kraal, na época em que não havia pagamentos em dinheiro ou em espécie. Os pagamentos obtidos durante a migração, segundo McClendon, chegavam a ser três vezes maiores que os pagos nas fazendas estudadas e também se transformavam em uma fonte de recursos para a compra de gado. A imposição dos labour bureaux contribui também para deixar os pais (chefes de kraal) ainda mais poderosos em relação aos filhos, pois, para migrar, era preciso tanto a permissão do fazendeiro, como do próprio pai.

Essa migração se constituiu, também, em uma fonte de tensão para os que ficavam no kraal. Ao encontrar melhores salários e condições de vida nas cidades, 
esses jovens, que constituíam a maior parte da força de trabalho nas fazendas, podiam simplesmente não retornar para casa no prazo estipulado (McCLENDON, 2002 , p. 116). Ao não retornar, eles expunham todos os membros do kraal à possibilidade de serem legalmente expulsos da terra, sem mencionar a vingança dos ancestrais, para os quais já não eram mais promovidos rituais.

Outra das fontes de incerteza levantadas na pesquisa de McClendon (2002), era a crescente restrição à posse da gado, na medida em que se expandiam as áreas agriculturáveis. Com pouco gado no kraal, os pais não poderiam honrar os compromissos de casamento de seus filhos e, com isso, também perdiam autoridade sobre eles, suas noras e netos. Ou seja, ao mesmo tempo em que a legislação de regulamentação da labour tenancy reforçava a autoridade paterna, ela tendia a minar as bases dessa autoridade cerceando a posse do gado. É importante também ressaltar que, no caso de morte do chefe do kraal, é o filho mais velho que assume a autoridade e a responsabilidade do contrato com os fazendeiros. Nesses casos, aqueles que se estabeleceram nas cidades são compelidos a voltar para o kraal, para que a terra da família não seja perdida ${ }^{17}$.

17. Para descrição contemporânea de um desses casos, ver Rosa (2011).

\section{Alguns Dados Contemporâneos}

Para aqueles que acompanham o texto até esse ponto, deve ser estranho encontrar uma seção de dados contemporâneos sobre uma categoria social e jurídica que havia sido condenada a desaparecer no final dos anos 1970. Na introdução do texto, havíamos mencionado que os labour tenants não apenas sobreviveram na prática, como também ganharam um novo estatuto jurídico em 1996. Curiosamente, uma das primeira leis que regulamentaram as noções de reforma agrária no pós-apartheid foi o Land Reform Act (lei 486, de 22 de março de 1996), que ficou conhecido como Labour Tenants Act, porque teve como alvo, justamente, a regulamentação da posse das terras ocupadas por essas famílias, teoricamente ou melhor, legalmente, inexistentes. Na esteira dos processos descritos acima a categoria apareceu assim definida:

"labour tenant" significa uma pessoa:

(a) que reside ou tinha o direito de residir em uma fazenda;

(b) que tinha ou tem o direito de cultivar ou de pastagem na fazenda referida no parágrafo (a) ou em outra fazenda do proprietário e como consequência deste direito provê ou provinha trabalho para o dono ou arrendatário; e

(c) cujos pais ou avós residem ou residiram em uma fazenda e tinham o direito de cultivar ou de pastagem naquela ou em outra fazenda do mesmo proprietário, e em consideração a tal direito proveem ou 
provinham trabalho para o proprietário ou arrendatário naquela ou em outra fazenda, incluindo a pessoa que for apontada como sucessor do labour tenant (...)".

Para aquelas pessoas que continuaram a viver nas fazendas, mas não prestavam mais serviços para antigos ou novos patrões, foi criada a categoria legal de occupiers (ocupantes), que é regulada pelo Extension of Security Tenure Act (ESTA), de 1997.

Utilizando a normatividade disponível a partir de 1996, diversas ONGs produziram pesquisas sobre a situação contemporânea dessas pessoas. A maioria dos dados disponíveis sobre os labour tenants na região de Kwazulu-Natal tem como fonte pesquisas realizadas pela Association For Rural Advancement (AFRA), uma ONG que atua na defesa do direito à terra para grupos excluídos durante o apartheid. Ao longo dos últimos anos, a AFRA produziu dois importantes relatórios sobre as condições de vida desses trabalhadores. Seguindo a categoria legal criada pelo programa de forma da terra, a AFRA classifica essa população (labour tenants e occupiers) como farm dwellers. Segundo o relatório (AFRA, 2008), dados de uma pesquisa encomendada pelo governo estimavam 495.345 pessoas vivendo nessa condição, apenas em Kwazulu-Natal.

Em um survey realizado na Municipality de Amajuba, com 50 famílias que viviam em fazendas, a mediana de moradores em cada kraal foi de 13 pessoas. Em termos de remuneração, os salários do trabalhadores rurais variava entre 500,00 e 1.300,00 rands (algo entre 125 e 410 reais por mês, conforme o câmbio de maio de 2012). É importante notar, porém, que, nos três distritos analisados na pesquisa, o percentual de famílias que efetivamente recebiam algum salário nas fazendas foi de 55,5\% para a cidade de Danhauser, $26 \%$ para a Newcastle e $58 \%$ em Emadlangeni. Ou seja, praticamente metade das famílias que vive nessas fazendas não trabalha de forma remunerada para os fazendeiros. A maior parte da renda monetária, portanto, é oriunda de empregos de familiares fora

18. Em diversos casos encontrados nas bases de dados da AFRA, fazendeiros trancavam os portões sem dar a chave aos moradores e permitiam a entrada somente em horários por eles estipulados.

19. Aproximadamente 52 e 225 reais por mês, ao câmbio de maio de 2012. das fazendas. Esses dados ajudam a revelar o constante movimento que precisa ser feito entre as fazendas e as cidades, por parte dos membros dessas famílias. Movimento controlado de perto pelo dono da terra, que mantém os portões, em geral, fechados com cadeado ${ }^{18}$.

Mais de $50 \%$ das famílias recebem algum tipo de "bolsa" do governo que pode ser para as crianças (210 rands por criança por mês) ou para aposentados (940 rands por mês $)^{19}$. No que concerne aos gastos de cada família, o relatório aponta para o fato de que suas maiores despesas são com comida (indicando que a alimentação é, em geral, comprada e não produzida no próprio lote), transporte (por força dos deslocamentos para trabalhos nas cidades e para chegar até as escolas) e em educação (na África do Sul, todos os alunos são obrigados a pagar 
taxas escolares em escolas públicas).

No survey de 2008, o $\mathrm{kraal}^{20}$ era visto pelos entrevistados como chefiado pela pessoa mais velha. A área, porém, era tida como pertencente a toda a família e não a esta pessoa (notemos que não há menção ao fazendeiro, proprietário legal da terra). Os kraals visitados eram habitados por até quatro gerações de uma família extensa. Como nos relatos da década de 1950, na maior parte dos casos, apenas as filhas solteiras (e seus filhos) e o filhos homens solteiros e casados habitam esses locais. Nas casas, todos aqueles considerados adultos e casais ocupam quartos separados, mas compartilham a cozinha e as casas rituais (ancestors buildings, no relatório).

Na pesquisa, foram listadas como partes do kraal as seguintes edificações: quartos de dormir para membros da famílias (cada unidade construída separada das demais); casa redonda para os ancestrais; cozinha comunal; depósito; quartos de visita; galinheiro; curral para gado, curral para cabras; horta de vegetais; latrina e covas. Todos eles eram são cercados e a maioria absoluta das construções feita de barro, o que implica a necessidade de manutenção periódica.

Nesse relatório, a casa redonda para o ancestrais é apontada, pelos entrevistados, como a casa da família. Essa casa - sempre feita de barro, que nunca pode ser demolida e que, quando cai, precisa ser reconstruída - é o local onde todos os membros da família, mesmo os que não mais residem no local, consultam os seus ancestrais ${ }^{21}$. Essas consultas não têm hora exata para acontecer, sendo resultado de uma complexa interpretação de sonhos e conselhos de familiares e amigos e que, portanto, não podem ser tratadas com a antecedência e o planejamento exigidos pelos fazendeiros.

Essas moradias, como aponta o relatório, são altamente dependentes de recursos exteriores a ele, como o barro para construir as casas, a grama para cobri-los, de madeira para cozinhar (apenas duas casas visitadas em Danhauser tinham luz elétrica), de água para beber e alimentar o animais e de pasto para o gado. Todos esses recursos, assim como as permissões para ir e vir, para enterrar parentes, para realizar rituais precisam ser negociados com os donos das fazendas diariamente. Tais negociações, que poderiam ser enquadradas provisoriamente sob rótulo do paternalismo, como o faz a literatura citada nas parte iniciais deste texto, se tornam ainda mais difíceis quando as fazendas são vendidas para novos proprietários ou quando a administração da propriedade passa de uma geração para outra.

Como apontam as descrições de Monteiro (2010), Borges (2008) e Steinberg (2002), a chegada de novos proprietários cria, em muitos casos, conflitos com os antigos trabalhadores. Por força do Extension of Security Act (ESTA), os
20. A AFRA utiliza a categoria household para descrever os domínios residenciais do labour tenants. Essa também é a forma utilizada pelas políticas públicas de restituição de terras.

21. Ver Borges (2010). 
farm dwellers que mantinham kraal, de forma consentida, nas fazendas antes de fevereiro de 1997, têm o direito de posse sobre essas terras. Sendo assim, quando um fazendeiro vende sua terra, ele repassa ao novo dono a relação anterior com os labour tentans residentes, que não podem ser expulsos ou removidos.

Nos maioria dos casos que conhecemos, os novos donos preferem não contar com o trabalho dessas pessoas e tendem a limitar seus direitos, quando muito, aos estritamente legais. Nessas circunstâncias ficam restritas as visitas, as áreas para recolher barro e grama para manutenção das casas, a pastagem para o gado e, a até mesmo, o acesso à luz e água potável. Também não há previsão legal específica relacionada às práticas religiosas. Quando privados dessas possibilidades, os moradores se veem diante daquilo se convencionou chamar de expulsão construída/despejo construtivo, ou seja, uma situação na qual a única alternativa de sobrevivência é deixar a fazenda. Tem sido nesses momentos que as famílias envolvidas passam a procurar os movimentos sociais, como o LPM, as ONGs ou políticos locais, para resolverem seus problemas. Nos arquivos da AFRA, estão registradas mais de 1.500 contendas desse tipo, em um prazo de menos de 10 anos.

22. Sobre as implicações antropológicas da busca de um lugar para morar entre os moradores de fazenda da região de Kwazulu-Natal, ver o trabalho de Borges (2011).

\section{Conclusão}

Como afirmei no início deste texto, apesar de ter sido tratada pela maior parte da literatura, a partir de sua condição social de trabalho, labour tenant, a vida coletiva da pessoas que residiram e ainda ocupam kraals, nas fazendas sul-africanas, não se resume a essa dimensão. Se é o trabalho, presente ou passado, para um fazendeiro que lhes garante direitos à terra, como assegura a lei de 1996, não é apenas ele que medeia sua relação com a terra em que vive. As relações de parentesco e religião, que aqui apareceram na forma de túmulos, gado, rituais, casas e ancestrais, estão diretamente associadas às suas reivindicações por terra.

Nesse sentido, o próprio uso sobreposto de termos como labour tenants (predominante na literatura e na legislação até o início dos anos 1990) e o de farm dwellers (nos casos recentes estudados por ONGs) reflete a própria dificuldade de se classificar os moradores de fazenda apenas por suas relações de trabalho. Os termos em Isizulu, utilizado pelas famílias que pesquisamos, abahlali basemapulazini denotam uma condição social de residência mais do que qualquer outra coisa22. Por isso, insistimos, nas partes finais, do texto em salientar a importância do kraal para a vida coletiva nas zonas rurais e urbanas.

Como vimos, com a ajuda da literatura, de algumas cenas de trabalho de campo 
e dos relatório de ONGs, o fato de residir em uma fazenda na qual se tem a posse e não a propriedade condiciona o modo de vida dessas pessoas, com fortes implicações sobre os modos de sua organização política. Essa dimensão que, deliberadamente, não foi explorada nesse texto, é peça chave para que, em investigações futuras, se compreenda as dificuldade que as ciências sociais, as ONGs e os próprios movimentos sociais, como o Landless People's Movement têm tido para organizar e legitimar suas demandas ${ }^{23}$. Vivendo na terra que reivindicam, se torna impossível e sem sentido para os abahlali basemapulazini, por exemplo, fazer uma ocupação - como o consagraram outros movimentos sociais de luta por terra que entram em diálogo com os sul-africanos, especialmente por meio da La Via Campesina. Do mesmo modo, qualquer afronta ao fazendeiro e seus direitos de proprietário, por meio de ações coletivas, pode resultar em um processo judicial que leve à expulsão legal (previstas na próprias leis que protegem seus direitos) das famílias, como descreve Monteiro (2010). Quando se tornam parte de um projeto de reforma da terra (e não de reforma agrária como explico em Rosa, 2012), eles não podem aceitar qualquer terra e em qualquer condição, como demonstra o caso do Sr. Impemdle trabalhado por Borges (2008).

Nossa experiência de contrastar a etnografia de eventos públicos com cenas da vida privada na região de Kwazulu-Natal tem mostrado que, nas situações que envolvem o Movimento, o Estado e as ONGs, a dimensão econômica e jurídica da terra adquire relevo. No entanto, quando estamos nas casas de farm dwlelers, temas como o gado, as relações familiares e as práticas religiosas ganham espaço considerável nas narrativas. Assim, por exemplo, o sem-terra se torna, a depender do contexto, também um sem família, sem casamento, sem gado ou sem ancestrais.

É por isso que defendemos que os moradores da fazenda são, na atual conjuntura sul-africana, uma categoria chave para compreender a questão da terra. Mais do que em qualquer outro grupo de demandantes, é entre eles que a oposição entre etnologia/sentimental/cultural e trabalho/econômico/agrário se torna absolutamente fluida.

Como a literatura e os casos apresentados ao longo do texto apontam, a luta dos moradores de fazenda sem-terra sul-africano se dá em vários tempos, processos e dimensões da vida social. Esses tempos e lugares não se limitam ao escaninhos sociológicos e políticos de uma narrativa branca e ocidental sobre a questão agrária, como foi a do campesinato, que reduziu, por exemplo, a noção família a uma unidade de produção (MAFEJE, 2003).

Esse é o desafio não apenas dos movimentos sociais e da ONGs, mas, principalmente, de uma sociologia da vida dos trabalhadores nas fazendas sul-africanas que conecte de forma mais justa o que chamamos, neste texto, de dimensões agrárias e etnológicas. Defendemos, no entanto, que essas conexões não se
23. Sobre o Landless People's Moment e seus dilemas ver os trabalho de Mngxitama (2006) e Greenberg (2006). 
ancorem necessariamente em novos conceitos (que, ao fim e ao cabo, sempre reificam a dinâmica de suas composições, como nos debates sobre indígenas e camponeses, por exemplo). Trata-se de uma questão de método na qual o foco seja a descrição das relações entre essas pessoas e a terra que reivindicam em diversos momentos de sua existência.

Abstract: This paper presents the results of a composition of literature review and field research on the Landless People's Movement struggles in South Africa aiming to explore the historical relation between the farm dwellers and the land they live's claim. Drawing from fieldwork notes, archives and literature debates, I state that the fluidity of this category, that embraces consequences of the apartheid, transformations in the agricultural sector, religion and customary laws affects their relations with the State, social movements and NGOs. This complexity also becomes problematic due to the fact that they cannot be easily described by the traditional sociological narratives designed for farm workers, peasants and neither with the one's of the classical African ethnology. Keywords: Farm Workers, South Africa, Fight for Land, Landless People, Apartheid.

\section{Referências}

AFRA. Special Report. Volume 1, Number 1, October, 2004.

. "This is our home - it is our land, our history and our right". Consolidated Verbatim Report, Farm dweller Workshops. May 2005. Pietermaritzburg, 2005.

Situational Analysis and Development Recommendations by and for Farm Dwellers in Amajuba District Council. Pietermarizburg, 2008.

ATKINSON, D. Going for Broke: the fate of the farmer workers in arid South Africa. Cape Town, HSRC Press, 2007.

BERGLUND, A.I. "Heaven-Herds: a study in Zulu symbolism". In: Michael G. Whisson and Martin West. Religion and Social Change in Southern Africa. Anthropological Essays in Honours of Monica Wilson. London/Rex Collings; Cape Town/ David Philip, 1975.

BORGES, A. "Sem sombra para descansar: etnografia de funerais na África do Sul contemporânea”. Anuário Antropológico, v. 2010, 2011, p. 215-252.

- "Uma propriedade, diversas propriedades: etnografia, comparação e distribuição de benefícios públicos no Brasil e na África do Sul”. In: Neiburg, F.; Sigaud, L.; Rosa, M.; Borges, A. e Macedo, M. (orgs) Brasil em Perspectiva. Rio de Janeiro, 7 Letras, 2010. 
. "À Corte: notas etnográficas sobre conflitos fundiários na África do Sul". In: Roberto Kant de Lima et al. (Org.). Reflexões sobre Segurança Pública e Justiça Criminal numa perspectiva comparada. Brasília: Secretaria Especial dos Direitos Humanos, 2008.

DU TOIT, A. "Farm Workers and the Agrarian Question". Review of African Political Economy, n. 61, 1994, pp. 375-388.

GOTLIB, J. Getting people back to land: interdependência entre governos e ong's na produção de beneficários por terra na província de Kwazulu-Natal, Africa do Sul. Dissertação (Mestrado em Sociologia e Direito) - Universidade Federal Fluminense, 2010.

GREeNBERG, S. "The Landless Peoples Movement and the failure of post-apartheid land reform". In: BALLARD, Richard; HABIB, Adam; VALODIA, Imraan (eds.). Voices of protest: social movements in post-apartheid South Africa. Pietermaritzburg: University of KwaZulu- Natal Press, 2006.

JAMES, D. Gaining Ground: rights and property in the South African Land Reform. London, Routledge-Cavendish, 2007

KUPER, A. Wives for Cattle: Bridewealth and Marriage in Southern Africa. London, Routledge and Paul Keagan, 1982.

. "Symbolic dimensions of the Southern Bantu homestead", Africa, n.50, vol. 1, 1980.

LATOUR, B. Reassembling the Social. An introduction to actor-network-theory. Oxford, Oxford University Press, 2005.

MAFEJE, A. "The Agrarian Question, Access to Land, and Peasant Responses in Sub-Saharan Africa". Civil Society and Social Movements Programme, Paper Number 6. United Nations Research Institute for Social Development, 2003. . "Religion, class and Ideology in South Africa". In: Wisson, G and West, M. (eds). Religion and social change in Africa. Cape Town/London, David Philip/ Rex Collings, 1975.

MARCUS, T. Modernising super-exploitation: restructuring South African Agriculture. London, Zed Books, 1989.

MCCLENDON, T. V. Genders and Generations Apart: Labor Tenants and Customary Law in Segregation-Era South Africa, 1920s to 1940s. Portsmouth: Heinemann, 2002. 
. "'Hiding Cattle on the White Man's Farm': Cattle Loans and Commercial Farms in Natal, 1930- 50". African Economic History, n. 25, 1997, p. 4358.

MNGXITAMA, A. "National Land Comitte, 1994-2004: a critical insider perspective". In: GIBSON, Nigel C., Challenging Hegemony: social movements and the quest for a new humanism in post-apartheid South Africa. Eritrea: African Word Press, 2006.

MONTEIRO, P. Desafiando o direito de propriedade: 0 embate entre diferentes concepções de direito à terra no contexto de reforma agrária sul-africana. Trabalho de Conclusão de Curso. (Graduação em Ciências Sociais) - Universidade Federal Fluminense, 2010.

MOYO, S.; YEROS, P. "The resurgence of rural movements under Neoliberalism". In: Sam Moyo e Paris Yeros (eds). Reclaiming the land: the resurgence of rural movements in Africa, Asia and Latin America. London, Zed Books, 2005.

NKUZI. Still Searching for Security. The reality of farm dweller evictions in South Africa. Polokwane, 2007.

NTSEBEZA, Lungisile. Democracy compromised. Chiefs and the politics of tha Land in South Africa, Leiden, Brill, 2005.

NTSEBEZA, L.; HALL, R. (eds.). The Land Question in South Africa: the Challenge of Transformation and Redistribution. Cape Town: HSRC Press, 2007.

ROBERTS, M. Labour in the farm economy. Johannesburg. South African Insitute of Race Relation, 1959.

ROBERTSON, H. M. "The economic conditions of the rural natives". In: I. Shapera, Western Civilization and the Natives of South Africa. Humanities Press, 1967.

ROSA, M. "Estado e ações coletivas na África do Sul e no Brasil: por uma sociologia contemporânea dos países não exemplares". Sociologias, 2008, v. 20, p. 292-318.

- "Mas eu fui uma estrela do futebol! As incoerências sociológicas e as controvérsias sociais de um militante sem-terra sul-africano". Mana (UFRJ. Impresso), v. 17, 2011, p. 365-394.

"Reforma agrária e land reform: movimentos sociais e o sentido de ser um sem-terra no Brasil e na África do Sul". Caderno CRH (UFBA. Impresso), v. 25, 2012, p. 99-114. 
SATO, C. Forced removals, land NGOs and community politics in KwaZulu-Natal, South Africa, 1953-2002. PhD Thesis, St. Anthony's College, University of Oxford, 2006.

SIGAUD, L. "As condições de possibilidade das ocupações de terra". Revista Tempo Social, São Paulo, SP, v. 17, 2005, n. 1, p. 255-280.

. "Honneur et tradition dans les plantations sucrières du nord-est (Brésil). Études Rurales, jan-juin, 1999, p. 211-228.

"Direito e coerção moral no mundo dos engenhos". Estudos Históricos, $\mathrm{n}^{\circ} 18,1996$, p. 361-387.

SPP. Forced Removals in South Africa. The SPP reports volume 4. Natal, Cape Town, SPP, 1983.

SUNDKLER, B. G. M. Bantu Prophets in South Africa. London Lutterwoth Press, 1948.

WILSON, F.; KOOY, A.; HENDRIE, D. Farm Labour in South Africa. Cape Town David Philip, 1997.

WALKER, C. Landmarked: Land Claims and Restitution in South Africa. Cape Town, Jacana, 2008. 